\title{
Safety and Efficacy of Different Doses of Misoprostol in Termination of Intrauterine Fetal Death (IUFD) Cases
}

\author{
SUNITA RANI DAS ${ }^{1}$, TABASSUM PARVEEN $^{2}, \mathrm{KN} \mathrm{NAHAR}^{2}$, BEGUM NASRIN², \\ SHAYELA SHAMIM ${ }^{3}$, SALEHABEGUM CHOWDHURY ${ }^{3}$
}

\begin{abstract}
:
Introduction: Misoprostol regimens for the induction of labor in second and third trimester IUFDs, in different doses range from 50 to $400 \mathrm{mcg}$ are all clinically effective. Larger doses of misoprostol potentially have an increased risk of adverse effects. If low dose of vaginal misoprostol have similar effectiveness than a higher dose used on its own, lower dose will impose dual benefit on patient in terms of less cost/risk of adverse effects.

Objective: To evaluate safety and efficacy of different doses of misoprostol in termination of IUD cases during the period from January to December, 2011 in the dept. of obs and gynae, BSMMU and Khulna Medical College Hospital.

Materials \& Methods: A randomized control trial was conducted with sixty IUD primi or multigravida cases having 28 to 42 weeks or more gestation, singletone pregnancy and Bishop's score 5 or less were included. Grand multiparas, women having history of previous caesarean section or myomectomy, transverse lie, placenta praevia were excluded from the study. The selected patients were randomly divided into two groups for termination using two different doses of misoprostol. Among 60 patients 30 (group -1) received $50 \mathrm{mcg}$ of misoprostol 6 hourly and 30 patients received (group -2) $100 \mathrm{mcg}$ of misoprostol 8 hourly per vaginally.

Outcome variables: Induction delivery time, number of delivery within 24 hours, mode of delivery, side-effects and complications of misoprostol were recorded. Pulse, BP, Temperature were noted every 4 hourly.

Result: Induction delivery time, mean $+S D$ was $21.7 \pm 9.47$ and $26.17 \pm 11.17$ hours respectively in group-1 and group-2, $(P=0.10)$. Number of doses required was, mean $\pm S D 2.67 \pm 0.9$ in group-1 and $2.08 \pm 0.81$ in group-2, the difference was statistically significant $(P<0.006)$. Delivery within 24 hours occurred in 20(66.67\%) cases in group-1 and in 16(53.33\%) in group-2.

Nausea, vomiting were present $16.67 \%$ and $10 \%$ in group-1 and $33.33 \%$ and $16.67 \%$ in group2 respectively. In both groups most of the cases had no side effect. In group-1 there was hyperstimulation in 2(6.67\%) cases and tachysystole in 1(3.33\%) case. In group-2 hyperstimulation and tachysystole developed in 4(13.33\%) and 2(6.67\%) cases respectively.

Conclusion: Both50mcg and100mcg intravaginal misoprostol are safe and effective in termination of intrauterine foetal death
\end{abstract}

\section{Introduction:}

Induction of labour in termination of IUD cases is associated with higher incidence of prolonged labour and cesarean delivery ${ }^{1}$. Oxytocin is safe and effective initiator of uterine contraction but success was contingent on the status of the cervix at the beginning of the induction ${ }^{2}$. Labour induction in presence of cervical immaturity was a common indication for use

1. FCPS Student, Dept of Obs and Gynae, BSMMU

2. Associate Professor, Dept of Obs and Gynae, BSMMU

3. Professor, Dept of Obs and Gynae, BSMMU 
of prostaglandin particularly prostaglandin E2 $2^{3-5}$. However in the last few years there has been considerable interest in the use of misoprostol for cervical ripening and labour induction ${ }^{6-11}$. Results of published trial suggest that misoprostol was both safe and effective but optimum dose and timing of administration of this medication for labour induction have not been clearly determined ${ }^{12}$. Misoprostol is a new synthetic analogue of prostaglandin E1. It has several advantages over other prostaglandins which includes low cost, easy storage at room temperature and favorable side-effects profiles ${ }^{13}$. Vaginal misoprostol has been extensively studied and a consensus exists as to its efficacy ${ }^{14-16}$. The aim of this study is to compare safety and efficacy of different doses of misoprostol in termination of IUD cases.

\section{Materials and methods:}

This prospective randomized controlled trial was conducted jointly in the Dept of obs and gynae, BSMMU and Khulna Medical College Hospital during the period from July to December, 2011. In this study total 60 IUFD cases of 28 to 42 weeks or more were included. Primi or multigravida, singleton pregnancy, cephalic or breech presentation and Bishop's score 5 or less were the inclusion criteria. Grand multiparas, women having history of previous caesarean section or myomectomy, transverse lie, placenta praevia were excluded from the study. Women having coagulopathy, hypersensitivity to prostaglandin and asthma were also excluded. On admission detailed history was taken and clinical examination was done and confirmation of IUFD was done using ultrasonogram. After proper counseling an informed written consent was taken from each patient. Per vaginal examination was done for evaluation of Bisop's score. The selected patients were randomly divided into two groups for termination using two different doses of misoprostol. For randomization a sequentially numbered sealed envelopes were used before termination. Among 60 patients 30 (group -1) received $50 \mathrm{mcg}$ of misoprostol
6 hourly and 30 patients received (group -2) 100mcg of misoprostol 8 hourly per vaginally.

In group -1 50mcg of misoprostol was administered 6 hourly intra-vaginally and in group- $2100 \mathrm{mcg}$ of misoprostol was administered 8 hourly up to starting of effective lalour pain. Then the total number of required doses to complete the procedure was recorded in the data collection sheet. Induction delivery time, number of delivery within 24 hours, mode of delivery, side-effects and complications of misoprostol were recorded. Pulse, BP, Temperature were noted every 4 hourly.

SPSS (version 12.0) statistical software was uses for data analysis. The result was expressed as the mean $( \pm S D)$, percentage and range. Comparison was done using $t$ test and chi square test, $p$ value $<0.05$ was considered significant.

\section{Results:}

Table 1 shows the socio - demographic condition of the study subject. Mean age of group-1 and group -2 was $24.53 \pm 5.21$ and $26.30 \pm 5.10$ years respectively $(P=.29)$. Mean gestational age of group-1 and group -2 was $34.67 \pm 3.67$ and $33.83 \pm 4.11$ weeks respectively $(P=0.4)$, there were no statistically significant difference between two groups regarding age and period of gestation and gravida.

Table II shows the Bishop's score of the study subjects. In group-1 Bishop's score was 2-5 in 8(26.67\%) cases and $4-5$ in 22(73.33\%) cases. In group-2 Bishop score was 2-3 in 10(33.33\%) and 4-5 in 20(66.67\%) cases.

Table III shows the comparison of out-come between 2 groups. Induction delivery time, mean+SD was $21.7 \pm 9.47$ and $26.17 \pm 11.17$ hours respectively in group-1 and group-2, $(P=0.10)$. Number of doses required was, mean $\pm S D 2.67 \pm 0.9$ in group- 1 and $2.08 \pm 0.81$ in group -2 , the difference was statistically significant $(P<0.006)$. Delivery within 24 hours occurred in 20(66.67\%) cases in group-1 and in $16(53.33 \%)$ in group-2.

Table-I

Socio-demography of the study groups

\begin{tabular}{lccc}
\hline Variables & Group-1 $(\mathrm{n}=30)$ mean $( \pm \mathrm{SD})$ & Group-2 $(\mathrm{n}=30) \mathrm{mean}( \pm \mathrm{SD})$ & $\mathrm{P}$-value \\
\hline Age $($ Yrs $)$ & $24.53 \pm 5.21$ & $26.30 \pm 5.10$ & $0.29^{\mathrm{NS}}$ \\
Gravida & $1.43 \pm 0.68$ & $1.67 \pm 0.76$ & $0.12^{\mathrm{NS}}$ \\
Gestational age $(\mathrm{Wks})$ & $34.67 \pm 3.67$ & $33.83 \pm 4.11$ & $0.41^{\mathrm{NS}}$ \\
\hline
\end{tabular}

NS= Not significant, Comparison was done using unpaired t test 
Table-II

Bishop's score between two groups

\begin{tabular}{lccc}
\hline Bishop's score & Group-150mcg & Group-2 100mcg & P - value \\
& 6 hourlyNo(\%) & 8 hourlyNo (\%) & \\
\hline $2-3$ & $8(26.67)$ & $10(33.33)$ & $0.47^{N S}$ \\
$4-5$ & $22(73.33)$ & $20(66.67)$ & \\
\hline Total & $30(100)$ & $30(100)$ & \\
\hline
\end{tabular}

NS= Not significant, Comparison was done using chi square test

Table-III

Comparison of outcome between two groups

\begin{tabular}{lccc}
\hline Outcome & Group-1 50mcg & Group-2 100mcg & P - value \\
& 6 hourly No (\%) & 8 hourly No (\%) & \\
\hline Induction delivery time (Hrs), Mean ( \pm SD)21.7 \pm 9.47 & $26.17 \pm 11.17$ & $0.1^{\text {NS }}$ \\
No. of dose required & $2.67 \pm 0.9$ & $2.08 \pm 0.81$ & $0.006^{S}$ \\
Delivery within 24 hours & $20(66.67 \%)$ & $16(53.33 \%)$ & $0.29^{\text {NS }}$ \\
\hline
\end{tabular}

$\mathrm{NS}=$ Not significant, $\mathrm{s}=$ significant, Comparison was done using unpaired $\mathrm{t}$ test

Table IV shows the mode of delivery between 2 groups. Out of 60 cases of IUD, all were delivered vaginally in both groups.

Table V shows the side effects misoprostol. Nausea, vomiting were present $16.67 \%$ and $10 \%$ in group-1 and $33.33 \%$ and $16.67 \%$ in group-2 respectively. In both groups most of the cases had no side effect.

Table VI shows the comparison of complication between 2 groups. In both the groups most of the patients did not develop any complications. In group1 there was hyperstimulation in 2(6.67\%) cases and tachysystole in $1(3.33 \%)$ case. In group-2 hyperstimulation and tachysystole developed in $4(13.33 \%)$ and $2(6.67 \%)$ cases respectively.

Table -VII shows the need of Oxytocin and blood transfusion between two groups. It is found that in group-1 4(13.33\%) cases and in group-2 7(23.33\%) needed oxytocin to augment labour pain, the difference was not statistically significant $(P=0.31)$.

Table-IV

Comparison of mode of delivery between two groups

\begin{tabular}{lcc}
\hline Mode of delivery & Group-1 50mcg 6 hourly & Group-2 100mcg 8 hourly \\
& No (\%) & No (\%) \\
\hline VD & $30(100)$ & $30(100)$ \\
LSCS & 0 & 0 \\
\hline Total & $30(100)$ & $30(100)$ \\
\hline
\end{tabular}

Table-V

Side effects misoprostol between two groups

\begin{tabular}{lccc}
\hline Side effects & Group-1 50mcg & Group-2 100mcg & P value \\
& 6 hourly No (\%) & 8 hourly No (\%) & \\
\hline No side effect & $22(73.33)$ & $14(46.67)$ & $0.17^{\text {NS }}$ \\
Nausia & $5(16.67)$ & $10(33.33)$ & \\
Vomitting & $3(10)$ & $5(16.67)$ & \\
Rise of Temp & 0 & $1(3.33)$ & \\
\hline Total & $30(100)$ & $30(100)$ & \\
\hline
\end{tabular}

NS= Not significant, Comparison was done using chi square test 
Table-VI

Comparison of complications between two groups

\begin{tabular}{lccc}
\hline complications & Group-150mcg & Group-2 100mcg & P -value \\
& 6 hourlyNo (\%) & 8 hourlyNo (\%) & \\
\hline No complication & $27(90.0)$ & $24(80.0)$ & $.56^{\text {NS }}$ \\
Hyperstimulation & $2(6.67)$ & $4(13.33)$ & \\
Tachysystole & $1(3.33)$ & $2(6.67)$ & \\
Total & $30(100)$ & $30(100)$ & \\
\hline
\end{tabular}

NS= Not significant, Comparison was done using chi square test

Table-VII

Comparison of Oxytocin and blood transfusion between two groups

\begin{tabular}{lccc}
\hline Variables & $\begin{array}{c}\text { Group-1 50mcg } \\
\text { 6 hourlyNo (\%) }\end{array}$ & $\begin{array}{c}\text { Group-2 100mcg } \\
\text { 8 hourlyNo (\%) }\end{array}$ & P value \\
\hline Oxytocin & 4 & 7 & $0.31^{\text {ns }}$ \\
Yes & 26 & 23 & \\
No & $30(100)$ & $30(100)$ & \\
Blood transfusion Not required & $30(100)$ & $30(100)$ & \\
\hline Total & &
\end{tabular}

NS= Not significant, Comparison was done using chi square test

\section{Discussion:}

The use of prostaglandins in termination of intrauterine fetal death has undergone a rapid evoluation. Prostaglandins had an effect on myometrial contractility and they also accelerate cervical ripening. Misoprostol, synthetic analogue of prostaglandin E1. It has several advantages over other prostaglandins which include low cost, easy storage at room temperature and favorable side effect profile. This study was aimed to evaluate the safety and efficacy of different doses of misoprostol in termination of IUFD cases.

In this study delivery within 24 hours was in $66.67 \%$ cases in group-1 and in $53.33 \%$ in group-2. Induction delivery time was shorter in group-1compared to group2 , mean+SD $(21.7 \pm 9.47$ vs $26.17 \pm 11.17)$, the difference was not statistically significant $(P=0.10)$. Wagaararachchi PT et al assessed the safety and efficacy of mefipristone in combination with misoprostol in termination of two groups of IUD cases. The average induction delivery time was 8.5 hours, $98 \%$ patients delivered within 72 hours. Induction delivery time was shorter with increasing gestation ${ }^{17}$.

Nyende $L$ et al compared the efficacy of vaginal misoprostol 200mcg 6 hourly with oral misoprostol $200 \mathrm{mcg} 6$ hourly. They found induction delivery time shorter with vaginal misoprostol (13.5 \pm 8.3$)$ compared to oral misoprostol $(21.4 \pm 13.9), p<0.05$. Here induction delivery time was shorter than present study ${ }^{18}$.

Chitacharoen $\mathrm{A}$ et al found induction delivery time of $18.87 \pm 10.38$ hours after giving $200 \mathrm{mcg}$ misoprostol vaginally in IUFD cases, $67.5 \%$ delivered within 24 hours and all delivered within 48 hours $^{19}$. According to Fawole $\mathrm{AO}$ et al mean induction delivery time was $17.5 \pm 6.3$ hours after administration of $400 \mathrm{mcg} 12$ hourly in 56 patients. In another randomized control trial of oral and vaginal misoprostol to manage 80 IUD cases $400 \mathrm{mcg}$ misoprostol was given orally 4 hourly and $200 \mathrm{mcg}$ misoprostol was administered vaginally 12 hourly. The study showed that the mean induction delivery time in oral group $(13.95 \pm 5.63 \mathrm{hrs})$ was significantly shorter that the time in vaginal group $(18.87 \pm 10.38 \mathrm{hrs} ; \mathrm{p}<0.001)^{20}$.

In previous studies a large range of doses of intravaginal and sublingual misoprostol used for induction were described, ranging from $100 \mathrm{mcg} 12$ hourly to400mcg 3 hourly ${ }^{18,20-23}$. Furthermore different doses were used at different gestational ages. One study recommended the following doses of misoprostol in missed abortion or IUD cases; $200 \mathrm{mcg}$ 6 hourly for gestational age of 13-17; 100mcg 6 hourly 
for gestational age of 28-26; $25-50$ mcg 4 hourly for gestational age of 27-43 weeks ${ }^{2}$.

In this study nausea, vomiting were present $16.67 \%$ and $10 \%$ in group- 1 and $33.33 \%$ and $16.67 \%$ in group2 respectively. Nyende L et al found more side effects (vomiting, diarrhea, shivering and pyrexia) with oral misoprostol (44.5\%) compared to vaginal mosoprostol $(20 \%)^{18}$. But in the present study there was no diarrhea, shivering. Studies showed that the use of misoprostol was associated with an increased incidence of tachysystole (defined as 6 or more uterine contraction in 10 minutes for two 10 minutes period) and hyperstimulation (uterine contraction lasting more than 90 seconds or more 5 contraction in 10 minutes). The incidence of hyperstimulation varies between 1 and 10 percent. In this study in group-1 there was hyperstimulation in $2(6.67 \%)$ cases and tachysystole in $1(3.33 \%)$ case. In group-2 hyperstimulation and tachysystole developed in $4(13.33 \%)$ and $2(6.67 \%)$ cases respectively. In this study no patient developed serious complications like DIC or rupture of uterus. In some studies more complications were found compared to the present study ${ }^{24-27}$.

In this study all IUFD cases delivered vaginally, no operative interference required.

\section{Conclusion:}

Both $50 \mathrm{mcg}$ and $100 \mathrm{mcg}$ intravaginal misoprostol are safe and effective in termination of intrauterine foetal death.But50mcg is safer as side-effects and complications were less, induction delivery time was shorter in case of $50 \mathrm{mcg}$ than $100 \mathrm{mcg}$. Delivery within 24 hours was higher in group -1. So $50 \mathrm{mcg}$ intravaginal misoprostol was more safe and effective in termination of IUD cases.

\section{References:}

1. Blanchette HA., Nayak S, Erasmus S. Comparison of the safety and efficacy of intravaginal Misoprostol (Prostglandin E1) with those of dinoprostone (Prostglandin E2) for cervical ripening and induction of labour in a community hospital. Am J Obstet Gynaecol June 1999;180(6):1551-1556.

2. American College of Obstetricians and Gynaecologists. Induction and augmentation of labour. Washington DC: 1995; ACOG Technical bulletin: 217 .
3. Nunes F, Rodrigues R, Meirinho M. Randomized comparison between intravaginal misoprostol and dinoprostone for cervical ripening and induction of labour. Am J Obstet Gynaecol June 1999; 181: 626-629.

4. Xenakis E, Piper JM, Conway DL, Langer O. Induction of labour in the nineties; Conquering the unfavorable cervix, Obstet Gynaecol 1997; 90: 235-9.

5. Orthu AAE. Induction of labour at term in primigravida with low Bishop's score: a comparison of three methods. Eur J Obstet Gynaecol Biol 1995; 58: 119-25

6. Fletcher HM, Mmitchells, Simecon D, Fredrick J, Brown D. Intravaginal misoprostol as a cervical ripening agent. Br. J Obstet Gynaecol 1993;100:641-4

7. Margulies M, Perez GC, Voto LS. Misoprostol to induce labour. Lancet 1993;339:64.

8. Bugalho A, Bique C, Pereira C, Granja AC, Bergstrom $S$. Uterine evacuation by vaginal misoprostol after second trimester pregnancy interuuption. Acta Obstet Scand 1996; 75: 270273

9. Bugalho A, Bique C, Machungo F, Faundes ALow dose vaginal misoprostol for induction of labour with a live fetus. Int J Obstet Gynaecol 1995; 49:149-55.

10. Rodrigues R, Nunes F, Tiago D, Avillez T, Veira $A$, Meirinho $M$, Induction of labour with a intravaginal administration of misoprostol. Int J Gynaecol Obstet 1998;60:233-7

11. Sanchez - Ramos L, Kaunitz AM, Del Valle GO, Delke I, Schroeder PA, Briones DK. Labour induction with the prostaglandin E1 methyl analogue misoprostol versus oxytocin: a randomized trial. Obstet Gynaecol 1993;81:332-6

12. Wing DA, Paul RH. A comparison of differing dosing regimens of vaginally administered misoprostol for preinduction cervical ripening and labor induction. Am J Obstet Gynaecol 1996;175:158-64

13. Scheepers SCJ, Van Erp EJM, van den Bergh AS. Use of misoprostol in first and second trimester abortion: a review. Obstet Gynaecol Surv 1999;54:592-600 
14. Gottschall DS, Borgida AF, Mihalek JJ, Sauer F, Rodis JF. A randomized clinical trial comparing misoprostol with prostaglandin E2 gel for preinduction cervical ripening. Am J Gynaecol 1997;177: 1067-1070.

15. Vara A, Herabutya y, Punyavachira P. A randomized trial of oral and vaginal misoprostol to manage delivery in cases of fetal death. Obstet Gynaecol 2003;101:70-73

16. Sanchez-Ramos L, Kaunitz AM, Wears RL, Delke I, Gaudier FL. Misoprostol for cervical ripening and induction of labour: A meta analysis. Obstet Gynaecol 1997;89:633-42

17. Wagaarachchi PT, Ashok PW, Narvekar NN, Smith NC, Templeton A. Medical management of late intrauterine death using a combination of mifepristone and misoprostol. BJOG 2002;109(4):443-7

18. Nyende L, Towoloba OA, Mabina MH. Comparison of vaginal and oral misoprostol, for the induction of labour in women with intrauterine fetal death. East Afr Med J. 2004;81(4): 179-82.

19. Chittacharoen A, Herabutya $Y$, Punyavachira $P$. A randomized trial of oral and vaginal misoprostol to manage delivery in cases of fetal death. Obstet Gynaecol. 2003; 101(1):70-3

20. Fawole AO, Adekunle AO, Sotiloye OS, Arowojolu AO, Otolorin EO. Experience with intravaginal misoprostol in the management of intrauterine fetal death. Afr J Med Sci 2004;33:105-8.
21. Eihassan EM, Abubaker MS, Adam I. Sublingual compared with oral and vaginal misoprostol for termination of pregnancy with second trimester fetal demise. Int J Gynaecol Obstet 2008;100:823.

22. Tang OS, Lau WN, Chan CC, Ho PC. A prospective randomized comparison sublingual and vaginal misoprostol in second trimester termination of pregnancy. Br J Obstet Gynaecol 2004;111:1001-5.

23. Blanchette HA, Nayak S, Erasmus S. Comparison of the safety and efficacy of intravaginal misoprostol (prostaglandin E2) for cervical ripening and induction of labour in community hospital. Am J Obstet Gynaecol 2001;108:952-959.

24. MacDorman MF, Kirmeyer S. Fetal and perinatal mortality, United States 2005. Nati Vital Stat Rep. 2009;57(8):1-19.

25. Gomez P, Wing D, Fiala C. Misoprostol for intrauterine fetal death. Int J Gynaecol Obstet 2007;99(suppl.2):190-3.

26. Nakintu N. A comparative study of vaginal misoprostol and intravenous oxytocin for induction of labour in women with intra-uterine fetal death in Malago hospital, Uganda. Afr Health Sci 2001;1:55-59.

27. Tang OS, Schweer H, Setberth HW, Lee SW, Ho PC. Pharmacokinetics of different routes of administration of misoprostol. Hum Reprod 2002;17:332-6. 